\title{
Contre une décadence programmée : le Don Quichotte à Alger de Waciny Laredj
}

\section{Leyla Guenatri}

\section{OpenEdition}

\section{Journals}

Édition électronique

URL : http://journals.openedition.org/recherchestravaux/402

DOI : $10.4000 /$ recherchestravaux.402

ISSN : 1969-6434

Éditeur

UGA Éditions/Université Grenoble Alpes

Édition imprimée

Date de publication : 30 juillet 2010

Pagination : 41-46

ISBN : 978-2-84310-174-8

ISSN : 0151-1874

Référence électronique

Leyla Guenatri, «Contre une décadence programmée : le Don Quichotte à Alger de Waciny Laredj », Recherches \& Travaux [En ligne], 76 | 2010, mis en ligne le 30 janvier 2012, consulté le 08 septembre 2020. URL : http://journals.openedition.org/recherchestravaux/402 ; DOI : https://doi.org/10.4000/ recherchestravaux.402 
Leyla GUENATRI

Université d'Alger

\section{Contre une décadence programmée : le Don Quichotte à Alger de Waciny Laredj}

\section{Parcours croisés et structuration identitaire}

Le programme narratif du roman de Waciny Laredj, Le Ravin de la femme sauvage ${ }^{\mathrm{I}}$, intitulé dans sa première publication $L a$ Gardienne des ombres ou Don Quichotte à Alger ${ }^{2}$, affleure déjà, à travers ces différents titres. En effet, il s'agit de l'entrecroisement de destins et de quêtes qui élisent comme lieu de rencontre privilégié l'espace textuel : le temps d'une écriture/lecture, s'enchevêtrent le récit de Don Quichotte, petit-fils de Cervantès, lancé sur les pas de son aïeul emprisonné en 1575 à Alger par les Turcs, les récits nostalgiques de Hanna, gardienne des ombres, grand-mère du narrateur Hsissen, et enfin le mythe littéraire 3 de la femme sauvage.

C'est précisément cette efflorescence qui rythme la narration et en densifie le schéma. La quête spéculaire introduite par les deux personnages-clés du récit s'installe : Don Quichotte arrière-petit-fils du célèbre Cervantès est touché par «la graine magique de l'écriture» (p. 2I). Tenté, comme le personnage dont il porte le nom, de se lancer sur les lieux que le romancier espagnol a hantés, il sacrifie à un devoir de mémoire et à un devoir de vérité; en effet, la quête d'une paternité perdue lui permet de revivre l'expérience ancestrale.

I. Éditions ENAG, Alger, 1997. Les références sont données entre parenthèses après les citations.

2. Éditions Marsa, 1996.

3. Ce mythe est largement évoqué par K. Yacine dans Nedjma, Le Cadavre encerclé, Les ancêtres redoublent de férocité et par R. Boudjedra dans L'Insolation. Les deux ravins existent bel et bien à Alger et à Constantine. 
Il communique cette passion à Hsissen, cadre du ministère de la Culture, qui désire lui aussi retrouver sa ville :

Faire découvrir la ville à Don Quichotte c'était aussi me la faire découvrir, à moi qui l'avais un peu oubliée : les détails s'estompent vite avec la peur. Cela me donnerait sans doute une nouvelle résistance intérieure dans cet environnement où tout était devenu non sens ou ambiguïté inédite. (p. 23)

À travers ce double parcours tracé par une vie (celle de Cervantès) et par l'itinéraire d'un héros (celui de Don Quichotte), sont reprogrammés un autre espacetemps et une double aventure.

Dans ce réel absurde et chaotique, les deux personnages recherchent le sens de leur existence individuelle et celle du groupe. Cette reconquête de la mémoire pour comprendre "l'ambiguïté inédite du présent", s'effectuera grâce aux visites guidées de l'Amirauté, "Le lieu qui garde le bruit des premiers pas de Cervantès dans ce pays, les premiers battements de son cœur et sa première peur» (p. 57), ou de la grotte, refuge de Cervantès en 1577. $\mathrm{Ou}$, comble de dérision, le récit nous conduit à la décharge publique de Oued Smar qui recèle des œuvres uniques du patrimoine culturel, comme la statue de Cervantès, le Cordello de Stein ou les Rêveries d'El Wahrani. Cette reconquête se fera aussi avec l'emprisonnement de Don Quichotte, l'«espion espagnol ", ce qui redouble l'épisode de la captivité de Cervantès. Suivant les traces de son aïeul, Don Quichotte finit par partager le même destin que lui, sur cette même terre et contre le même pouvoir.

Hsissen suit de son côté son propre schéma narratif, en essayant, à travers son parcours initiatique, de décoder les secrets de la ville. Ainsi parvient-il, véritable conscience malheureuse, à percer au plus profond le système à la fois politique et symbolique de cette ville énigmatique à plus d'un titre. En parcourant le labyrinthe de la cité avec Don Quichotte, le narrateur redécouvre la mémoire, estompée par la peur et l'angoisse d'une existence plongée dans la terreur. Il réapprend à se libérer des images de mort véhiculées au quotidien par les actes terroristes. En racontant à son compagnon l'histoire de la ville, de ses vestiges et celle des hommes qui y ont vécu, Hsissen se délivre de son malaise existentiel. C'est ce qui lui donne la volonté de s'attaquer à d'autres forces, au pouvoir qui accusera l'étranger d'espionnage. Le séjour forcé de deux personnages au commissariat, puis en prison, dénonce l'arbitraire et l'absurdité d'un système aux abois, redoutant le regard inquisiteur de l'autre. Soucieux de préserver l'intégrité et la liberté de son ami, Hsissen se trouve broyé par les rouages terribles du système répressif. Il perdra ainsi "la langue et le sexe» pour avoir osé défier les puissants. 
Les drames vécus par ces deux personnages, dont le destin semble soudé un temps, sont à lire comme des rites de passage, en mesure de transformer profondément leur conscience du vécu. L'appréhension d'une réalité en crise ${ }^{4}$, noyée dans ses complexités socio-historiques, s'éclaire à la lumière des épreuves subies par l'un et l'autre. Don Quichotte venu visiter le lieu magique, la grotte ancestrale, tombe sur un chaos urbain, une ville qui a perdu ses repères et noue une amitié sincère avec les plus dignes de ses enfants: Hsissen, Hanna, Maya. La ville revivra, idéalisée par l'histoire et la mémoire de ceux qui la racontent. Ce texte est donc le fruit d'une conscience meurtrie, mûrie par la tragédie au quotidien et par l'épreuve ultime de la captivité. Don Quichotte restera donc, comme son ancêtre, marqué par «la débâcle de ce monde lié au mensonge et au spectacle plutôt qu'à la profondeur des choses» (p. 19). Mais comme l'affirme le personnage dans sa lettre à Hsissen : "l'absurdité peut aussi nous mener à la découverte de nous-mêmes» (p. IOI). C'est ainsi qu'il prend conscience, qu'au-delà de la cité exsangue et déchirée, «Une autre ville est en train de naître en moi, peut être en nous tous.» (p. IOo)

Les rebondissements souvent dramatiques du récit, la mise en spectacle de la quête reconstituent la dialectique du même et de l'autre. La quête mythique, culturelle, idéologique du petit-fils, la découverte d'une ville agitée par les soubresauts d'une crise multidimensionnelle en compagnie de Hsissen, Hanna ou Maya, réalisent la confrontation des personnages avec le passé, mais aussi avec l'amère réalité présente. La dialectique du même et de l'autre s'enrichit lors des moments de rencontre : ainsi Don Quichotte redécouvre, heureux, la grotte de Cervantès grâce aux efforts de Hsissen et visite l'Amirauté, jadis port d'escale de son aïeul; il revit aussi, grâce au contact chaleureux avec Hanna, la grand-mère de Hsissen qui raconte les fastes du passé andalou de ses ancêtres. Corrélativement, la quête culturelle devient éclairage référentiel et questionnement idéologique. Dès son arrivée, Don Quichotte réveille l'animosité des autorités sur sa présence : il est étranger, indésirable, hors-la-loi, ce qui justifiera son incarcération arbitraire. C'est cet emprisonnement qui lui fera prendre conscience qu'il séjourne dans un pays confronté à des contradictions internes profondes :

Cette terre est si étrange qu'elle devient au fil de la découverte de plus en plus fascinante et effrayante en même temps un amour fragile. (p. II6)

Loin d'être l'ennemi à abattre comme le voit le système, Don Quichotte est le regard distancié qui redonne sens au chaos, ne serait-ce qu'en recherchant

4. Voir à ce sujet, M. Lacheraf, "Réflexions culturelles et politiques sur la société algérienne», El Watan, 2 juin 1998. 
le pourquoi de tel fait absurde ou de telle incongruité. Il interpelle le réel et aide Hsissen à éclairer les mécanismes qui actionnent la machine infernale. Le regard étranger est donc bien regard privilégié.

\section{Écriture carnavalesque : jeu d'ambiguiité et/ou jeu de vérité}

Ce dévoilement s'effectue grâce à certaines stratégies discursives dont la plus prégnante demeure l'écriture carnavalesque. Waciny Laredj use de ce jeu scripturaire, s’appuyant sur la dérision pour dévoiler, dénoncer, juger, discuter «les problèmes ultimes de l'existences" ». Les situations "extrêmes» de fantasmagorie accentuent la liberté du langage, délivrent des tabous et du monologisme. La mise en spectacle de situations grotesques vécues par des personnages bouffons permet de traduire, par le rire, la tragédie du réel et l'éclatement de l'unité de l'homme. L'identité duelle et ambivalente s'affirme, en effet, comme un principe de structuration du monde et de l'individu. Ainsi, dès sa dénomination, accentuée par sa stature - Don Quichotte, "d'où sortait-il avec un nom pareil ?» (p. I7) - se dessine l'image du personnage mythique, affrontant par monts et par vaux les atrocités du monde : "C'était bien le grand Don Quichotte, comme s'il venait de sortir d'un livre pour se faire une vie autre que celle imaginée.» (p. 19) La figure emblématique créée par Cervantès revit dans une autre fiction, reformulant le sens du mythe littéraire. De même, le nom du narrateur, Hassen, transformé en Hsissen (un diminutif attribué par la grand-mère Hanna) met l'accent sur la puérile naïveté, la "vision ambiguë» du personnage, son insuffisante perception «des véritables réalités et enjeux ${ }^{6} »$. Mais cette vision se clarifiera au fur et à mesure des épreuves vécues et de leur mise en langage.

Le système est lui aussi copieusement dénaturé à travers des dénominations grotesques : «Banou kalboun» ou encore «La famille des verts» ou «Les hommes de paille». Ces appellations lapidaires dénoncent, au delà du symbolisme des images, la fonction sociale de ces hommes, traduisant le mépris qui leur est réservé par ces surnoms. De même, l'inversion/perversion de la fonction des espaces culturels amplifie le discours de la dérision. Ainsi, la fameuse grotte de Cervantès, censée être un haut lieu commémoratif, est transformée en sale décharge, en zoubia sghira qui ne signifie plus rien. Complètement délabré, hanté par les enfants et les ivrognes, ce lieu de

5. J. Kristeva, «Le mot, le dialogue et le roman», Recherches pour une Sémanalyse, Seuil, I969, p. I04.

6. W. Laredj, interview accordée par l'auteur à la revue Algérie-littérature-action, reproduite à la fin du roman. 
mémoire tombé dans l'oubli traduit bien les effets pervers du vide culturel et de l'amnésie populaire.

Le discours pompeux du ministre lors de la visite officielle au lieudit Cervantès accentue encore la négation du lieu et de l'homme qui y a séjourné. Cervantès reste le «roumi venu prendre les richesses du pays et convertir les gens à la religion des roumis» (p. 63). Idée que ne partagent pas, bien entendu, Hsissen et les autres personnages qui ont une autre vision de l'histoire :

Don Quichotte a fait son devoir envers l'humanité et il nous reste à accomplir le nôtre [...] Il est espagnol, mais aussi algérien. Nous le revendiquons aujourd'hui [...] (p. 30)

Paradoxalement la visite de Don Quichotte et de Hsissen à la grande décharge révèle, cachées sous les détritus, les œuvres les plus chères du patrimoine culturel. La présence de Hanna, la grand-mère aveugle du narrateur, réfugiée dans ses récits, accrochée à la résurgence du passé prestigieux de son Andalousie natale, est symbolique à plus d'un titre : elle figure, au delà de la perte de toutes les réalités dysphoriques, une mémoire vivante de ce qui constitue le fond hispano-mauresque de la culture algérienne. En même temps, elle traduit un besoin de rencontre, de convergence avec la culture espagnole, riche elle-même de tous les sédiments mauresques dont elle a hérité. La rencontre symbolique entre ces deux figures délirantes, Don Quichotte et Hanna, révèle le besoin fondamental d'ouverture à l'autre, signe de richesse intérieure et de tolérance, comme pour aller à contre-courant des valeurs négatives du présent.

Enfin, le harcèlement du représentant de la culture, en la personne de Hsissen meurtri dans sa chair par l'arbitraire du système, et l'emprisonnement de Don Quichotte, figure mythique de la culture universelle, achèvent la mascarade et révèlent la manifestation d'une «décadence programmée ${ }^{7}$ » par "des choix conservateurs». Le discours de la dérision amplifie le monologisme, fait éclater son unicité, l'exhibe dans ses mécanismes aliénants et s'ouvre sur l'hétérogène.

La figure héroïque et ambivalente de Don Quichotte dédoublée par le personnage de Hsissen permet la réconciliation de la fiction et du réel à travers leur permanente tension. Waciny Laredj, en représentant la figure mythique dans son accoutrement contemporain, lui délègue une nouvelle vie, une énergie à même de redonner au combat donquichottesque une mémorable

7. M. Lacheraf, «Survol d'une époque menacée», El Watan, I3 août I998. 
actualité en rapport avec les conflits de l'Algérie moderne, en quête de repères civilisationnels. L'auteur peut ainsi révéler son projet et contribuer à lui donner une dimension universelle :

Ce qui m'intéresse dans tout cela, dit-il, ce ne sont pas les guerres, elles ont un commencement et une fin, mais plutôt ce désir et la force qui les sous-tend de donner du sens à une vie qui est en train de perdre tout sens, et peu importe si ce sens est erroné historiquement. Un monde est en train de fléchir, finissant dans l'absurdité qui laisse place à un monde nouveau avec d'autres valeurs et, pourquoi pas plus d'ambiguïtés. ${ }^{8}$

La réactivation du combat humanitaire de Don Quichotte en quête de vie et de vérité transcende ainsi toutes les formes d'aliénation, de dépossession culturelle, idéologique et littéraire. Lancé à la dure conquête de l'espace maghrébin, Don Quichotte retrouve comme Cervantès ses racines mauresques et, grâce à sa conviviale fraternité, désintègre les discours de l'exclusion, de l'intolérance et de la répression".

8. W. Laredj, interview reproduite à la fin du roman, p. I70.

9. L'auteur a fait paraître un livre très intéressant, intitulé Sur les traces de Cervantès, aux Éditions Alpha d'Alger; il précise que faire le voyage de Cervantès à Alger n'est pas un retour à l'histoire des $\mathrm{XVI}^{\mathrm{e}}$ et $\mathrm{XVII}^{\mathrm{e}}$ siècles, mais un moyen de revivre le partage quand les temps sont durs : un simple rappel presque désespéré, pour un monde qui s'autodétruit sans s'en rendre compte... 